\title{
Glucagon-Like Peptide 1 Receptors in Nucleus Accumbens Affect Food Intake
}

\author{
Amanda M. Dossat, Nicole Lilly, Kristen Kay, and Diana L. Williams \\ Department of Psychology and Program in Neuroscience, Florida State University, Tallahassee, Florida 32306-4301
}

Central glucagon-like peptide 1 receptor (GLP-1R) stimulation suppresses food intake, and hindbrain GLP-1 neurons project to numerous feeding-relevant brain regions. One such region is the nucleus accumbens (NAc), which plays a role in reward and motivated behavior. Using immunohistochemical and retrograde tracing techniques in rats, we identified a robust projection from GLP-1 neurons in the nucleus of the solitary tract to the NAc. We hypothesized that activation of NAc GLP-1Rs suppresses feeding. When injected into the NAc core of rats at doses subthreshold for effect when administered to the lateral ventricle, GLP-1 significantly reduced food intake relative to vehicle at 1,2 , and $24 \mathrm{~h}$ posttreatment. The same doses had no effect when injected into the NAc shell. NAc core treatment with ventricle-subthreshold doses of the GLP-1R antagonist exendin (9-39) caused significant hyperphagia at $2 \mathrm{~h}$ posttreatment, suggesting that endogenous stimulation of NAc core GLP-1Rs plays a role in limiting food intake. It has been suggested that GLP-1 can cause nausea, but we found that NAc core administration of GLP-1 did not cause a conditioned taste aversion to saccharin, suggesting that the anorexic effect of NAc core GLP-1 is not caused by malaise. Finally, we observed that NAc core injection of GLP-1 significantly increased c-Fos expression in the NAc core. We conclude that that GLP-1Rs in the NAc play a physiologic role in food intake control, and suggest that the GLP-1 projection to NAc core may link satiation signal processing in the hindbrain with forebrain processing of food reward.

\section{Introduction}

Hindbrain glucagon-like peptide 1 (GLP-1) neurons are hypothesized to play a role in the control of food intake (Hayes et al., 2010). These cells are located primarily in the nucleus of the solitary tract (NTS) and project throughout the brain to many feeding-relevant areas (Rinaman, 2010). GLP-1 neurons are activated by meal-related stimuli, including gastric distention (Vrang et al., 2003), and many studies have demonstrated that GLP-1 injection into the cerebral ventricles. reduces food intake (Turton et al., 1996; Williams et al., 2009a). Conversely, chronic blockade of central GLP-1 receptors (GLP-1R) with intracerebroventricular antagonist treatment increases food intake and body weight, and RNA interference-mediated knockdown of mRNA for preproglucagon, the precursor of GLP-1, in the NTS also causes hyperphagia and weight gain (Barrera et al., 2011). Together, these loss-of-function studies support the idea that neuronal GLP-1 plays a physiologic role in the maintenance of energy balance. GLP-1R agonists are now used clinically in humans for treatment of type 2 diabetes, and in addition to their effects on glucose homeostasis, they also reduce appetite and body weight (Bradley et al., 2010). For these reasons, it is critical

\footnotetext{
Received June 27, 2011; revised Aug. 9, 2011; accepted Aug. 15, 2011

Author contributions: D.L.W. designed research; A.M.D., N.L., K.K., and D.L.W. performed research; A.M.D. and D.L.W. analyzed data; A.M.D. and D.L.W. wrote the paper.

This work was supported by NIH Grant DK078779 (to D.L.W.). We acknowledge the expert technical assistance of Ryan Diaz, Kiersten Mullis, and Alexis Pizzi.

The authors declare no financial conflicts of interest.

Correspondence should be addressed to Diana L. Williams, Box 3064301, Florida State University, Tallahassee, FL 32306-4301.E-mail: williams@psy.fsu.edu.

DOI:10.1523/JNEUROSCI.3262-11.2011

Copyright $\odot 2011$ the authors $\quad 0270-6474 / 11 / 3114453-05 \$ 15.00 / 0$
}

to determine which GLP-1R-expressing neuronal populations mediate these effects.

Experiments in which GLP-1R agonists and antagonists are administered intracerebroventricularly suggest that GLP-1R populations across the brain play a role in mediating GLP-1's effects, but such studies do not identify specific nuclei. Thus far, the paraventricular nucleus of the hypothalamus (PVN) is the only identified site where direct injection of low doses of GLP-1 reduces food intake (McMahon and Wellman, 1998). The PVN has high GLP-1 fiber density and GLP-1R expression (Merchenthaler et al., 1999; Tauchi et al., 2008), but a number of other feeding-relevant brain regions also receive GLP-1 projections and contain GLP-1R. Here, we focused on the nucleus accumbens (NAc) as a potential site of action for central GLP-1. In the rat, both the NAc core and shell contain GLP-1 fibers and GLP-1R (Merchenthaler et al., 1999; Rinaman, 2010). The NAc is well known for its role in drug addiction and reward-motivated behavior, and it is established that manipulations of NAc can affect food intake (Berridge et al., 2010). Perhaps the most well studied example is the increase in intake of high-fat food elicited by intra-NAc injection of the $\mu$-opiod receptor agonist DAMGO (Will et al., 2003). We hypothesized that NAc GLP-1 receptor activation reduces food intake, and that endogenous GLP-1 action in NAc plays a physiologic role in the control of ingestion. First, we characterized the GLP-1 neuron projection to NAc using retrograde tracing and immunohistochemistry. We then examined the effects of injection of GLP-1 or the GLP-1R antagonist exendin (9-39) (Ex9) into the NAc, and provide evidence that the NAc core is a GLP-1-sensitive region. Together, our data supports the idea that the GLP-1 projection to NAc is involved in food-intake control. 


\section{Materials and Methods}

Animals

Naive male Wistar rats (mean body weight $325 \mathrm{~g}$ at the start of experiments; Charles River Laboratories) were maintained individually in temperature-controlled vivariums on a 12-h-light:12-h-dark cycle in plastic cages with food hoppers. Distilled water and rat chow (Purina) were available ad libitum except where otherwise noted. Rats were handled daily and habituated to experimental procedures before the studies. All experimental procedures were approved by the Florida State University Institutional Animal Care and Use Committee and conform to the standards of the Guide for the Care and Use of Laboratory Animals (National Research Council 1996).

\section{Retrograde tracing}

Injections. Rats received unilateral $0.5 \mu \mathrm{l}$ microinjections of $4 \%$ Fluorogold ( $n=3$; Fluorochrome) or Red RetroBeads $(n=3$; Lumaflor) into the NAc core under $2-4 \%$ isoflurane in $1 \mathrm{~L}$ oxygen/min inhaled continuously during surgery. Each rat was injected in two locations with a $30 \mathrm{G}$ Hamilton microsyringe (VWR) and pump (World Precision Instruments) at a rate of $100 \mathrm{nl} / \mathrm{min}$ for Fluorogold and $300 \mathrm{nl} / \mathrm{min}$ for RetroBeads. Stereotaxic coordinates for the first injection were $1.5 \mathrm{~mm}$ lateral to midline, 1.2 or $1.5 \mathrm{~mm}$ anterior to bregma, and $7.4 \mathrm{~mm}$ ventral to skull surface. The second injection was $2.0 \mathrm{~mm}$ anterior to bregma at the same lateral and ventral coordinates. Carprofen $(5 \mathrm{mg} / \mathrm{kg}$, s.c.; Butler Schein Animal Health Supply) was administered before surgery. Body weights were monitored during recovery.

Perfusions. At 3 (for RetroBead-injected rats) or 5 (for Fluorogoldinjected rats) days postinjection, rats were anesthetized $(180 \mathrm{mg} / \mathrm{kg}$ ketamine and $30 \mathrm{mg} / \mathrm{kg}$ xylazine, i.p.) and transcardially perfused with 10 mM PBS and 4\% paraformaldehyde. Brains were removed and sunk in $30 \%$ sucrose in PBS and then frozen in isopentane on dry ice. Coronal cryostat sections $(20 \mu \mathrm{m})$ through the NAc were slide-mounted for injection placement verification and stored at $-80^{\circ} \mathrm{C}$, while coronal microtome sections $(40 \mu \mathrm{m})$ through the NTS were collected into $0.02 \mathrm{M}$ TBS with $0.1 \%$ sodium azide and stored at $4^{\circ} \mathrm{C}$.

Immunohistochemistry. Staining for GLP-1 followed a previously described protocol (Rinaman, 1999). Antibodies were diluted in $0.3 \%$ Triton-X, $1 \%$ BSA, and $1 \%$ normal donkey serum in $10 \mathrm{~mm}$ PBS. The rabbit anti-GLP-1 primary (Bachem) was diluted at 1:5000 and the secondary for RetroBead-containing sections was 1:500 donkey anti-rabbit Alexa-488 (Invitrogen). The secondary for Fluorogold-containing sections was 1:1000 donkey anti-rabbit Cy3 (Jackson Immunoresearch). RetroBead-containing sections were mounted and coverslipped with Fluoro-Gel (Electron Microscopy Sciences). Fluorogold-containing sections were double-labeled for Flurogold. Because both primaries were rabbit, these sections were incubated in $10 \%$ normal rabbit serum in $0.3 \%$ Triton-X and $1 \%$ BSA in PBS for $2 \mathrm{~h}$ followed by overnight incubation with 1:100 donkey anti-rabbit IgG Fab fragment (Jackson Immunoresearch) before incubation with 1:3000 rabbit anti-Fluorogold (Millipore). The secondary was 1:500 donkey anti-rabbit Alexa-488 (Invitrogen), and these sections were mounted and coverslipped with Aqua Polymount (Polysciences). Control sections incubated without primaries or without secondaries showed no staining. Control sections from Fluorogold-injected rats were stained for GLP-1 and went through all subsequent steps except for incubation with the anti-Fluorogold primary. These sections showed no donkey anti-rabbit Alexa-488 binding.

Analysis. Tracer injection placement was verified by examination of sections through NAc. From each rat, we assessed a series of 16 alternating sections through the caudal NTS, $\sim 14.16 \mathrm{~mm}$ through $15.24 \mathrm{~mm}$ posterior to bregma (Paxinos and Watson, 2007). Slides were examined with an Olympus BX41 fluorescence microscope and monochromatic digital images were acquired with a Retiga EXI Aqua camera and Q-Capture software (Hunt Optics). We used Adobe Photoshop CS4 to adjust contrast, add color, and merge images of tracer and GLP-1 immunoreactivity. RetroBead injections diffused only within $\sim 1 \mathrm{~mm}$ of the medial NAc core injection sites, whereas Fluorogold injections diffused throughout NAc core and shell and reached neighboring structures in some cases. Therefore, we only quantified sections from RetroBead- injected rats. GLP-1-labeled cells, RetroBead-containing cells, and cells containing both were counted by eye.

\section{Food intake experiments}

Cannulation. Rats were implanted with 26G guide cannulas (Plastics One) targeting the lateral ventricle (LV) or NAc core or shell as described previously (Williams et al., 2009a). Coordinates for the LV were $1.5 \mathrm{~mm}$ lateral to midline, $0.9 \mathrm{~mm}$ posterior to bregma, and $2.7 \mathrm{~mm}$ ventral to skull surface. NAc core coordinates were $1.2 \mathrm{~mm}$ anterior to bregma, 1.5 $\mathrm{mm}$ lateral, and $4.9 \mathrm{~mm}$ ventral to skull surface. NAc shell coordinates were $0.8 \mathrm{~mm}$ lateral, $1.5 \mathrm{~mm}$ anterior to bregma, and $5.9 \mathrm{~mm}$ ventral to skull surface. Injectors (30G) used in the experiments extended $2.0 \mathrm{~mm}$ (for LV) or $2.5 \mathrm{~mm}$ (for NAc) below the end of the guide cannulas. LV cannulation was verified through observation of water drinking induced by Angiotensin II (Sigma-Aldrich). All placements were verified histologically after behavioral experiments ended.

LV administration studies. Within-subjects counterbalanced designs $(n=10)$ were used to determine the dose-response for food intake effects of LV-injected GLP-1 and Ex9 (American Peptides). On experiment days, food was removed $2 \mathrm{~h}$ before the onset of the dark cycle. One hour before dark, rats received an LV injection of $0,0.033,0.15,0.3,1$, or $3 \mu \mathrm{g}$ of GLP-1 in $2 \mu \mathrm{l}$ saline. Food was returned immediately before dark and intake was measured 1, 2, and $24 \mathrm{~h}$ later. Body weight was recorded daily and injections were separated by at least $48 \mathrm{~h}$. The feeding responses to $0,2.5,5,10$, or $20 \mu \mathrm{g}$ of $\mathrm{Ex} 9$ in $2 \mu \mathrm{l}$ saline were then examined using the same protocol with the same rats.

NAc administration studies. We chose doses of GLP-1 and Ex9 that had no significant effect on food intake in the LV dose-response studies. Injections and feeding measurements were performed as described above, except injection volume was $0.5 \mu \mathrm{l}$. To determine the effect of intra-NAc core GLP-1, we examined the feeding response to saline versus $0.025 \mu \mathrm{g}$ of GLP- 1 in one group of rats $(n=7)$, and then the effect of saline versus $0.1 \mu \mathrm{g}$ of GLP- 1 in a second group $(n=8)$. Another group of NAc core-cannulated rats $(n=8)$ received saline and 1,2 , or $3 \mu \mathrm{g}$ of Ex9 in counterbalanced order. Rats with NAc shell-targeted cannulas $(n=11)$ received saline and 0.025 or $0.1 \mu \mathrm{g}$ of GLP-1 in counterbalanced order.

\section{Conditioned taste aversion}

To determine whether intra-NAc core GLP-1 produces conditioned taste aversion (CTA), we used a previously described protocol (Oberbeck et al., 2010) in which intra-NAc core saline or $0.1 \mu \mathrm{g}$ of GLP-1, or intraperitoneal injection of $1 \mathrm{ml}$ of $0.6 \mathrm{M} \mathrm{LiCl}$ ( $n=5$ /group) was paired with $0.02 \%$ saccharin. Rats were given ad libitum access to a $0.02 \%$ saccharin and water on the following day and intakes were measured for $24 \mathrm{~h}$.

\section{GLP-1-induced c-Fos}

NAc core-cannulated rats from the feeding experiments were used in this study. Food was removed $2 \mathrm{~h}$ before treatment and rats were divided into two groups: intra-NAc core injection of saline $(n=5)$ or $0.1 \mu \mathrm{g}$ of GLP-1 $(n=7)$. Ninety minutes postinjection, rats were anesthetized and transcardially perfused as described above. Coronal cryostat sections $(20 \mu \mathrm{m})$ were slide-mounted and stained for c-Fos as previously described (Williams et al., 2009b) using rabbit anti-c-fos primary (EMD Biosciences) and donkey anti-rabbit Alexa-488. Photographs were taken as described above, and Image (NIH) was used to count c-Fos-like immunoreactivity bilaterally on four or five sections through NAc surrounding the site of injection. Sections through the center of injection were excluded so that tissue damage-related artifact was not mistakenly counted as c-Fos.

\section{Statistical analysis}

Data are reported as mean \pm SEM. Effects were evaluated by pairedsamples Student's $t$ test or within- or between-subjects one-way ANOVA, as appropriate. Post hoc comparisons were made with Tukey's Honestly Significant Difference test. $p$ values of $<0.05$ were considered significant.

\section{Results}

Colocalization of retrograde tracer with GLP-1

Neurons positive for GLP-1 were observed throughout the caudal NTS with highest density near the level of the obex. Few were 


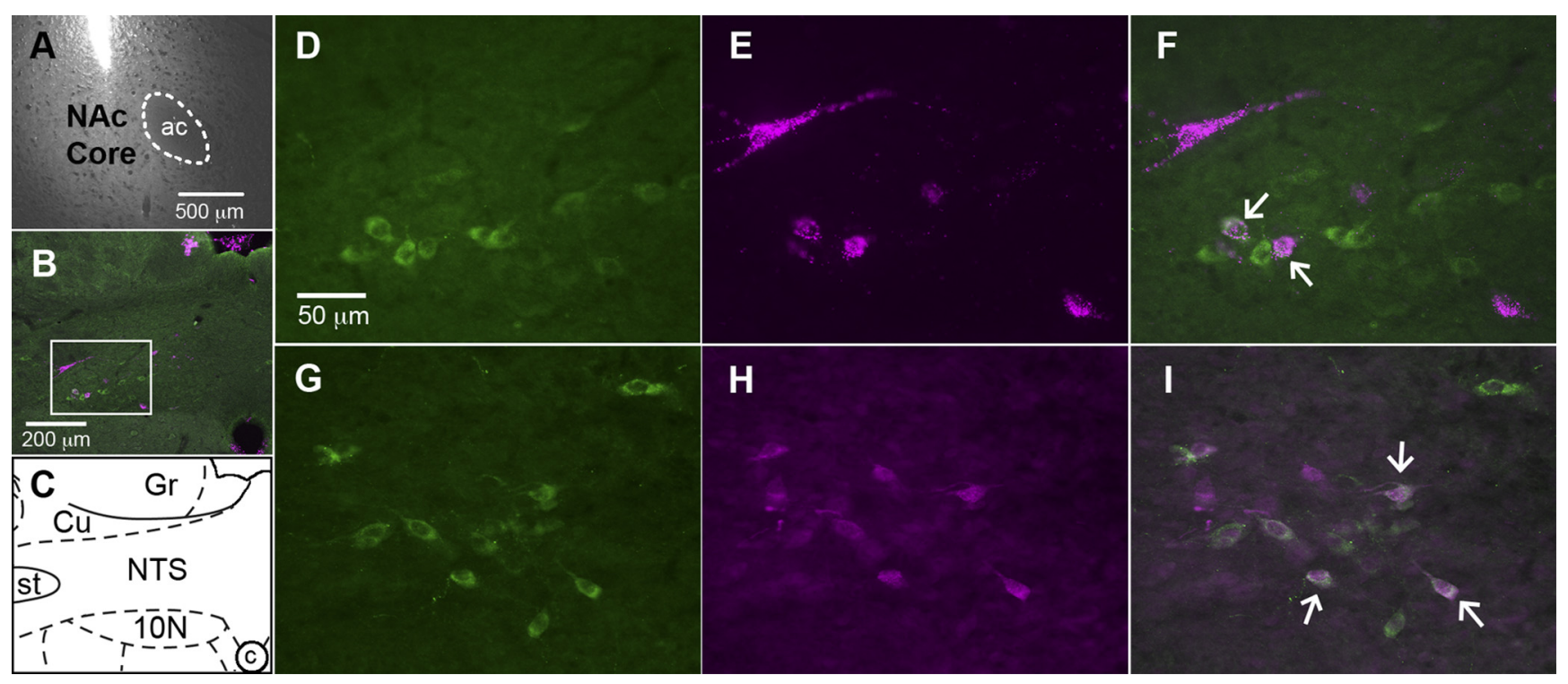

Figure 1. Representative images of fluorescent immunostaining and retrograde tracing of the projection from NTS neurons to NAc. $A$, NAc image showing the location and minimal spread of RetroBead injection (ac, anterior commissure). B, C, A low-magnification image of the caudal NTS (B) and a corresponding diagram (C) based on Paxinos and Watson (2007) are provided for orientation ( $C$, cuneate nucleus; $G r$, gracile nucleus; st, solitary tract; $10 \mathrm{~N}$, dorsal motor nucleus of the vagus; $C$, central canal). Higher-magnification images are taken from the area inside the white box in $\boldsymbol{B} . \boldsymbol{B}, \boldsymbol{D}, \boldsymbol{F}, \boldsymbol{G}, \boldsymbol{I}, G L P-1$ neurons (green cytoplasmic fluorescence) are visible in the NTS. $\boldsymbol{B}, \boldsymbol{E}, \boldsymbol{F}, \boldsymbol{H}, \boldsymbol{I}$, Magenta cytoplasmic fluorescence identifies neurons that are retrogradely labeled by RetroBeads $(\boldsymbol{B}, \boldsymbol{E}, \boldsymbol{F})$ or Fluorogold $(\boldsymbol{H}, \boldsymbol{I}) \cdot \boldsymbol{B}, \boldsymbol{F}, \boldsymbol{I}$, Colocalization of GLP-1 and tracer is shown by merging images of GLP-1 and tracer. Arrows indicate several double-labeled cells.
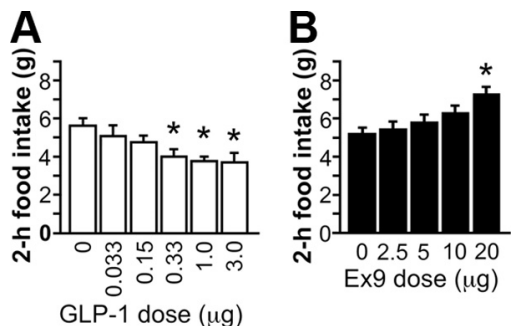

Figure 2. $\quad A, B$, Dose-response function for the food intake effects of LV-injected GLP-1 ( $A)$ and $\operatorname{Ex} 9(B) .{ }^{*} p<0.05$ relative to saline.

observed at the caudal-most level of the area postrema and none were observed anterior to that point. Retrograde tracer was found throughout the caudal NTS and colocalized with GLP-1 in many cells (Fig. 1). We identified 251.0 \pm 2.45 GLP-1 neurons and $180.0 \pm 23.79$ RetroBead-containing neurons. Among these, $65.67 \pm 8.04$ were both GLP-1- and RetroBead-positive. Thus, $26.21 \pm 3.4 \%$ of NTS GLP-1 neurons were retrogradely labeled. Among all retrogradely labeled caudal NTS neurons, $37.8 \pm 8.1 \%$ were GLP-1-positive.

\section{GLP-1 and Ex9 effects on food intake}

LV injection of 1 and $3 \mu \mathrm{g}$ of GLP- 1 reduced food intake relative to saline at 1 and $2 \mathrm{~h}$ postdark onset $(p<0.01)$, while lower doses did not differ from saline (Fig. $2 A ; 1 \mathrm{~h}$ data not shown). There were no significant effects on $24 \mathrm{~h}$ intake or body weight. LV treatment with $20 \mu \mathrm{g}$ of Ex9 increased food intake at 1 and $2 \mathrm{~h}$ postdark onset $(p<0.01)$, with no effect of lower doses (Fig. $2 B$; $1 \mathrm{~h}$ data not shown). At $24 \mathrm{~h}, 20 \mu \mathrm{g}$ of Ex9 was still effective (saline, $24.61 \pm 1.33 \mathrm{~g} ; 20 \mu \mathrm{g}$ of Ex9, $29.4 \pm 1.11 \mathrm{~g} ; p<0.01$ ).

\section{Effects of intra-NAc treatment}

NAc cannula placements are illustrated in Figure $3 A$. Intra-NAc core injection of 0.025 and $0.1 \mu \mathrm{g}$ of GLP-1 each reduced food intake relative to saline at 1 and $2 \mathrm{~h}$ postdark onset $(p<0.05)$
(Fig. $2 \mathrm{~B} ; 1$ h data not shown). A significant effect was observed at $24 \mathrm{~h}$ (saline, $25.1 \pm 0.9 \mathrm{~g} ; 0.025 \mu \mathrm{g}, 23.0 \pm 1.0 \mathrm{~g} ; 0.1 \mu \mathrm{g}, 23.3 \pm$ $0.8 \mathrm{~g} ; p<0.05$ for each dose vs saline). Body weight was not affected. NAc shell injection of the same doses had no effect on food intake or body weight at any point measured (Fig. $2 B$ ).

As shown in Figure $3 C$, NAc core injection of $3 \mu \mathrm{g}$ of Ex9 $(p<$ $0.001)$ effectively increased food intake at $2 \mathrm{~h}$ posttreatment. There was a main effect of Ex9 at $24 \mathrm{~h}\left(F_{(3,18)}=3.54, p<0.05\right)$ with a trend toward increased intake after $3 \mu \mathrm{g}$ of Ex9 (saline, $26.1 \pm 1.37 \mathrm{~g} ; 3 \mu \mathrm{g}, 29.06 \pm 1.17 \mathrm{~g} ; p=0.08$ ), but no effect on body weight.

\section{Conditioned taste aversion}

Rats preferred saccharin after it was paired with intra-NAc core saline injection, and rats in the NAc core $0.1 \mu \mathrm{g}$ of GLP-1 group were not significantly different (Fig. 3D). Rats in the control group given $\mathrm{LiCl}$ displayed an aversion to saccharin ( $\mathrm{LiCl}$ vs saline and GLP-1, ps $<0.001)$.

\section{c-Fos induction}

Intra-NAc core injection of $0.1 \mu \mathrm{g}$ of GLP-1 substantially increased the number of c-Fos-positive nuclei in the NAc core region (mean number of c-Fos-positive cells per section, counted bilaterally: saline, $112.2 \pm 32.7$; GLP-1, $544.5 \pm 37.6$; $p<0.001$; Fig. 4). Although the injections were unilateral, c-Fos expression was similar on the injected and noninjected sides. The boundary between core and shell is difficult to delineate without counterstaining, but few cells in the shell region contained c-Fos immunoreactivity.

\section{Discussion}

Our results support the hypothesis that the GLP-1 neuronal projection to the NAc plays a physiologic role in the control of food intake. Retrograde tracer injections into the medial NAc core identified a strong GLP-1 projection to this forebrain region. GLP-1 injection directly into the NAc core suppressed intake at doses that were subthreshold for effect when delivered to the LV. 

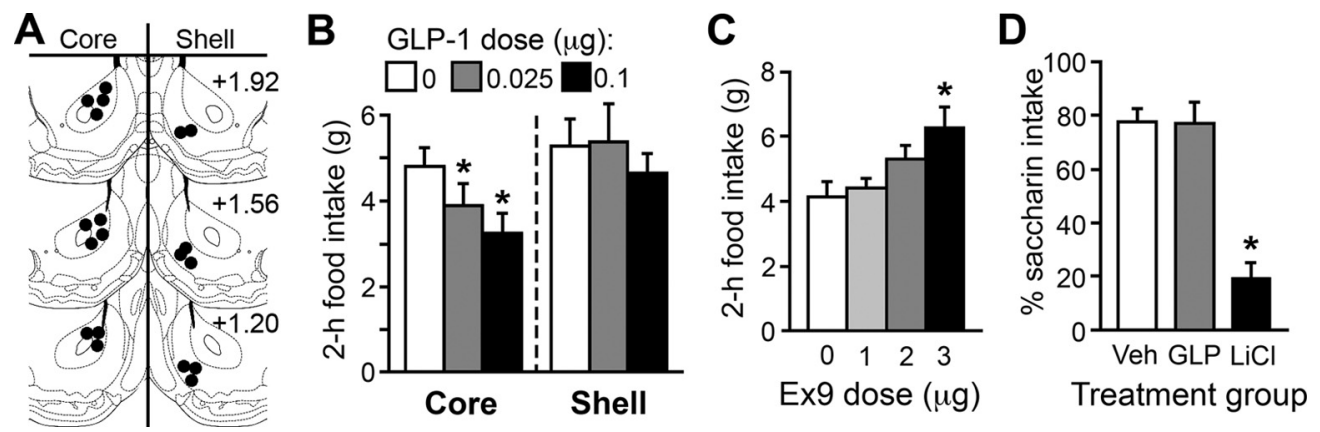

Figure 3. A, Diagram of representative NAc core and shell injection placements based on the atlas of Paxinos and Watson (2007). Additional rats' injections were identified in similar locations at points between the anterior-posterior levels shown here. $\boldsymbol{B}$, NAc core, but not shell, injection of GLP-1 reduced food intake. $\boldsymbol{C}$, Ex9 injected into the NAc core increased feeding. $\boldsymbol{D}$, Percentage of saccharin out of total saccharin plus water consumed in a $24 \mathrm{~h}$ test of CTA. Rats that previously experienced saccharin paired with intra-NAc core saline or GLP-1 strongly preferred to drink saccharin over water, but rats that received a saccharin-LiCl pairing showed aversion to saccharin. ${ }^{*} p<0.05$ relative to saline.

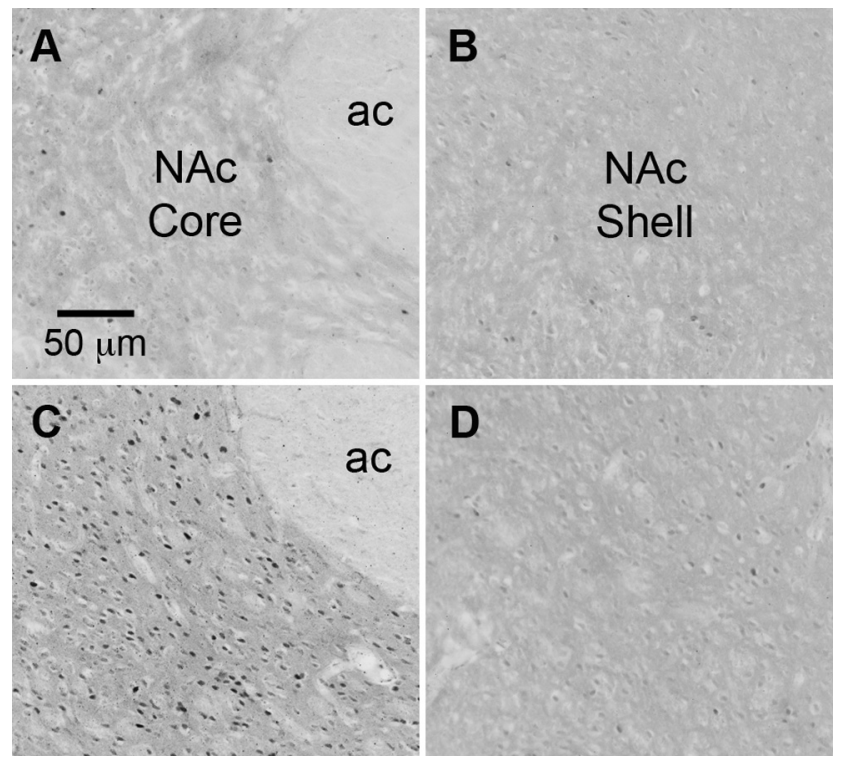

Figure 4. $\quad \boldsymbol{A}-\boldsymbol{D}$, Representative images of $\mathrm{C}-$ Fos immunoreactivity (dark nuclear staining) in the NAc of a rat that received intra-NAc core saline ( $\boldsymbol{A}$, core region; $\boldsymbol{B}$, shell region) and a rat that received intra-NAc core GLP-1 ( $\boldsymbol{C}$, core region; $\boldsymbol{D}$, shell region). ac, Anterior commissure.

Our findings suggest that the core is more relevant for GLP-1 action than the shell, because intra-NAc shell injection of the same doses of GLP-1 had no effect. We observed significant c-Fos induced by intra-NAc core GLP-1 as well, adding confidence to the conclusion that NAc core neurons are GLP-1-responsive. These effects demonstrate that responses can be driven by pharmacologic GLP-1R activation in NAc core, but do not necessarily mean that endogenous GLP-1 release in NAc has any impact on feeding. Our demonstration that intra-NAc core Ex9 treatment increased food intake addresses this issue and supports the conclusion that neuronal GLP-1 release at this site plays a role in limiting food consumption.

Central GLP-1Rs have been implicated in the response to visceral illness in several studies. LV or third intracerebroventricular injection of GLP-1 causes CTA (Thiele et al., 1997; Kinzig et al., 2002), and blockade of GLP-1R impairs LiCl-induced anorexia and formation of CTA (Seeley et al., 2000). Therefore, it is important to consider the possibility that the effects of intra-NAc GLP-1 observed here are related to illness responses and not to the control of food intake under normal physiologic circumstances. The fact that NAc core Ex9 treatment increased food intake goes some way to address this issue. None of the manipulations in this experiment are known to cause malaise, so it seems unlikely that this hyperphagic response could be due to relief from visceral illness. Rather, we suggest that this Ex9-induced hyperphagia reveals a role of endogenous GLP-1 in the physiologic control of food intake. To further address this issue, we asked whether intra-NAc core GLP-1, at a dose that significantly reduced food intake, could also produce a CTA. Rats treated with $\mathrm{LiCl}$ showed a robust CTA, but intra-NAc core GLP-1 produced no aversion. Together, our data support the suggestion that the anorexia we observed after NAc GLP-1 treatment is not due to viscerosensory stress.

GLP-1Rs expressed in different brain regions appear to play different functional roles. Previous investigations have identified the PVN as a nucleus in which GLP-1 affects food intake, but PVN GLP-1 treatment has no effect on glucose homeostasis and does not produce a CTA (McMahon and Wellman, 1998; Sandoval et al., 2008). The present study adds the NAc core as a second site for GLP-1's food intake effects without induction of CTA. GLP-1 injected into the NAc shell had no effect on feeding, and it remains to be seen what other effects may be obtained with shell GLP-1R stimulation. In contrast to the effects obtained with PVN or NAc core treatment, injection of GLP-1 into the central nucleus of the amygdala causes CTA without affecting food intake (Kinzig et al., 2002). GLP-1Rs are also expressed in the arcuate nucleus of the hypothalamus (ARC), an area known to be important for food intake control. GLP-1 action in the ARC, however, affects glucose homeostasis and not food intake (Sandoval et al., 2008). Therefore, while there is some overlap, different GLP-1 neuronal projections are not entirely redundant with one another in terms of the physiologic and behavioral processes they influence.

The present studies focused on neuronal GLP-1, but it is established that intestinal GLP-1 and peripheral GLP-1R play a role in food intake control as well (Williams, 2009). GLP-1 can cross the blood-brain barrier freely (Kastin et al., 2002), but it is unlikely that GLP-1 released from the intestine reaches brain GLP-1R because the half-life of the active form of GLP-1 is $<2$ min (Holst and Deacon, 2005). However, this is not the case for the degradation-resistant GLP-1R agonists exendin-4 and liraglutide. A recent study suggests that the longer-term (i.e., $24 \mathrm{~h}$ ) anorexic effects of peripheral injection of these agonists are in fact mediated by brain GLP-1Rs (Kanoski et al., 2011). This raises the question of whether NAc GLP-1Rs may play a role in mediating the effects of peripherally administered exendin- 4 or liraglutide. Because humans now use these agonists in type 2 diabetes treatment, this issue has clinical relevance. 
Research on the role of the NAc in food intake control has focused in particular on hedonic intake-ingestion in the absence of homeostatic need, due to factors such as pleasure or reward obtained by eating. Although the NAc has been implicated in hedonic eating, it has not been considered to play a major role in the homeostatic control of food intake (Kelley et al., 2005). Conversely, GLP-1 has been considered a player in homeostatic feeding, with mediatory roles in meal-related satiety (Hayes et al., 2009) and the central effects of the adiposity hormone leptin (Goldstone et al., 1997). NTS GLP-1 neurons receive direct vagal afferent input (Hisadome et al., 2010) and are activated by gastric distention (Vrang et al., 2003) and ingestion of palatable, energydense food (Gaykema et al., 2009). Based on the data presented here, we hypothesize that meal-related signals from the gastrointestinal tract promote the release of GLP-1 in the NAc, where stimulation of GLP-1R act to reduce food intake. This GLP-1 projection to NAc may be the first identified behaviorally relevant connection between hindbrain satiety-processing neurons and a rostral forebrain region involved in reward.

\section{References}

Barrera JG, Jones KR, Herman JP, D’Alessio DA, Woods SC, Seeley RJ (2011) Hyperphagia and increased fat accumulation in two models of chronic CNS glucagon-like peptide-1 loss of function. J Neurosci 31:3904-3913.

Berridge KC, Ho CY, Richard JM, DiFeliceantonio AG (2010) The tempted brain eats: pleasure and desire circuits in obesity and eating disorders. Brain Res 1350:43-64.

Bradley DP, Kulstad R, Schoeller DA (2010) Exenatide and weight loss. Nutrition 26:243-249.

Gaykema RP, Daniels TE, Shapiro NJ, Thacker GC, Park SM, Goehler LE (2009) Immune challenge and satiety-related activation of both distinct and overlapping neuronal populations in the brainstem indicate parallel pathways for viscerosensory signaling. Brain Res 1294:61-79.

Goldstone AP, Mercer JG, Gunn I, Moar KM, Edwards CM, Rossi M, Howard JK, Rasheed S, Turton MD, Small C, Heath MM, O'Shea D, Steere J, Meeran K, Ghatei MA, Hoggard N, Bloom SR (1997) Leptin interacts with glucagon-like peptide-1 neurons to reduce food intake and body weight in rodents. FEBS Lett 415:134-138.

Hayes MR, Bradley L, Grill HJ (2009) Endogenous hindbrain glucagon-like peptide-1 receptor activation contributes to the control of food intake by mediating gastric satiation signaling. Endocrinology 150:2654-2659.

Hayes MR, De Jonghe BC, Kanoski SE (2010) Role of the glucagon-likepeptide-1 receptor in the control of energy balance. Physiol Behav 100:503-510.

Hisadome K, Reimann F, Gribble FM, Trapp S (2010) Leptin directly depolarizes preproglucagon neurons in the nucleus tractus solitarius: electrical properties of glucagon-like peptide 1 neurons. Diabetes 59:1890-1898.

Holst JJ, Deacon CF (2005) Glucagon-like peptide-1 mediates the therapeutic actions of DPP-IV inhibitors. Diabetologia 48:612-615.

Kanoski SE, Fortin SM, Arnold M, Grill HJ, Hayes MR (2011) Peripheral and central GLP-1 receptor populations mediate the anorectic effects of peripherally administered GLP-1 receptor agonists, liraglutide and exendin-4. Endocrinology 152:3103-3112.
Kastin AJ, Akerstrom V, Pan W (2002) Interactions of glucagon-like peptide-1 (GLP-1) with the blood-brain barrier. J Mol Neurosci 18:7-14.

Kelley AE, Baldo BA, Pratt WE (2005) A proposed hypothalamic-thalamicstriatal axis for the integration of energy balance, arousal, and food reward. J Comp Neurol 493:72-85.

Kinzig KP, D'Alessio DA, Seeley RJ (2002) The diverse roles of specific GLP-1 receptors in the control of food intake and the response to visceral illness. J Neurosci 22:10470-10476.

McMahon LR, Wellman PJ (1998) PVN infusion of GLP-1-(7-36) amide suppresses feeding but does not induce aversion or alter locomotion in rats. Am J Physiol 274:R23-R29.

Merchenthaler I, Lane M, Shughrue P (1999) Distribution of pre-proglucagon and glucagon-like peptide-1 receptor messenger RNAs in the rat central nervous system. J Comp Neurol 403:261-280.

Oberbeck DL, McCormack S, Houpt TA (2010) Intra-amygdalar okadaic acid enhances conditioned taste aversion learning and CREB phosphorylation in rats. Brain Res 1348:84-94.

Paxinos G, Watson C (2007) The rat brain in stereotaxic coordinates. New York: Academic.

Rinaman L (1999) Interoceptive stress activates glucagon-like peptide-1 neurons that project to the hypothalamus. Am J Physiol 277:R582—R590.

Rinaman L (2010) Ascending projections from the caudal visceral nucleus of the solitary tract to brain regions involved in food intake and energy expenditure. Brain Res 1350:18-34.

Sandoval DA, Bagnol D, Woods SC, D’Alessio DA, Seeley RJ (2008) Arcuate glucagon-like peptide 1 receptors regulate glucose homeostasis but not food intake. Diabetes 57:2046-2054.

Seeley RJ, Blake K, Rushing PA, Benoit S, Eng J, Woods SC, D'Alessio D (2000) The role of CNS glucagon-like peptide-1 (7-36) amide receptors in mediating the visceral illness effects of lithium chloride. J Neurosci 20:1616-1621.

Tauchi M, Zhang R, D’Alessio DA, Stern JE, Herman JP (2008) Distribution of glucagon-like peptide-1 immunoreactivity in the hypothalamic paraventricular and supraoptic nuclei. J Chem Neuroanat 36:144-149.

Thiele TE, Van Dijk G, Campfield LA, Smith FJ, Burn P, Woods SC, Bernstein IL, Seeley RJ (1997) Central infusion of GLP-1, but not leptin, produces conditioned taste aversions in rats. Am J Physiol 272:R726-R730.

Turton MD, O'Shea D, Gunn I, Beak SA, Edwards CM, Meeran K, Choi SJ, Taylor GM, Heath MM, Lambert PD, Wilding JP, Smith DM, Ghatei MA, Herbert J, Bloom SR (1996) A role for glucagon-like peptide-1 in the central regulation of feeding. Nature 379:69-72.

Vrang N, Phifer CB, Corkern MM, Berthoud HR (2003) Gastric distension induces c-fos in medullary GLP-1/2-containing neurons. Am J Physiol Regul Integr Comp Physiol 285:R470-R478.

Will MJ, Franzblau EB, Kelley AE (2003) Nucleus accumbens mu-opioids regulate intake of a high-fat diet via activation of a distributed brain network. J Neurosci 23:2882-2888.

Williams DL (2009) Minireview: Finding the sweet spot: peripheral versus central glucagon-like peptide 1 action in feeding and glucose homeostasis. Endocrinology 150:2997-3001.

Williams DL, Baskin DG, Schwartz MW (2009a) Evidence that intestinal glucagon-like peptide-1 plays a physiological role in satiety. Endocrinology 150:1680-1687.

Williams DL, Baskin DG, Schwartz MW (2009b) Hindbrain leptin receptor stimulation enhances the anorexic response to cholecystokinin. Am J Physiol Regul Integr Comp Physiol 297:R1238-R1246. 